\title{
Experiences of Parents in their Children's' Education: a case of Kieni West District, Nyeri County, Kenya
}

\author{
Professor Thuranira Simon ${ }^{1}$, Ndirangu, Lydiah M..$^{2 *}$ \\ ${ }^{1}$ (Department of Education and Social Sciences, Embu University College, Kenya) \\ ${ }^{2 *}$ (Department of Education and Social Sciences, Kenya Methodist University,,Kenya)
}

\begin{abstract}
Parents play an invaluable role in laying the foundation for their children learning. This study was set to investigate the experiences of parents in their children's education in twenty one public secondary schools in Kieni West District in Nyeri County-Kenya. The objectives of this study were to :(i)Investigate the nature of experiences parents face in their children's education.(ii)Establish the extent of interaction between parents and teachers and (iii) to explore views about the experiences faced by parents in their children's education. Twelve public secondary schools were randomly selected. The population of the study was five thousand three hundred and eighty one students. In total, 130 form three students, 76 teachers and 113 parents participated in this study. The research study employed both qualitative and quantitative techniques in collecting and analyzing data. The study purposively sampled form three students. The study used two sets of instruments namely: questionnaire for teachers and students and a structured interview schedule for parents. These instruments were piloted for reliability and validity. Measures of central tendency such as mode, mean, median, frequency and standard deviation were used to present the findings of the study. Results based on research area indicated that $73 \%$ of the parents lacked school fees and $79.8 \%$ of the parents experienced difficulties and painful experiences during their time .Poor education background of the parents and lack of adequate time to assist their children affected their level of involvement. Further $98.2 \%$ of the parents felt that organized parental involvement programmes can improve their relationship with their children. Major recommendations included among others identifying sourced of funds to aid in school fees and holding parent's awareness programmes.
\end{abstract}

Key words: Parents' involvement. Children's education, poor education background, parents' conferences, organized parental involvement programmes.

\section{Introduction}

Family is the first source for teaching on how to behave and how to make decisions in life. One of the aspects that has received attention by many researchers is children's academic achievement (Bradley \& Corwyn, 2002). Parents play a significant role in their children's moral thinking (Grusec, Goodnow \& Kuezynski, 2000). Parental aspiration is in turn influenced by the child's evident achievement. The more the child achieves, the greater is the parental expectation. Ryan (2005) reported that academic achievement is positively related to having parents who enforce rules at home. Conflicting work schedules and competing demands on parents' time have been cited as barriers to parent's involvement in schools. This refers to parents with odd work schedules or those who must work more than one job; it is also possible to find parents who feel they don't have the time given that they are busy with their leisure interests and activities (Dwyer \& Hecht, 2001).Some parents have had enough discouraging experiences with parent involvement that they feel weary of trying to include or involve parents as partners. The most universal problem is poor attendance at school events that deal with educational topics, convey important information or require work to be done (Kirschenbaum, 2000). Asking busy parents to participate in the school rarely produces significant results (Greenleaf, 2000). Due to inconsistency of participation across all parents, teachers feel concerned that creating and incorporating too many parent involvement activities may pose problems in that not all children are receiving such parental assistance.

Today, parental involvement in education of their children is one of the most important on-going discussions in the field of education. There is a remarkable boost to the learners' academic success when parents are involved in their education (Eliason \& Jenkins, 2003). In some cases, more attention is given on the decline of educational achievement among students. Children have two main educators in their lives: their parents and their teachers at school. Some parents may feel that their participation is not necessary given that their child is doing well in school and others may have no history of being involved and see no reason to begin doing so (Dwyer \& Hecht, 2001). Many parents have experiences going through school. These parents may have encountered academic difficulties or other painful experiences during their time in school. Many parents do not want to become involved because they question their ability to make a difference. Studies show that some parents are not very much involved in all aspects of their children's education due to frequent barriers like scheduling conflicts and lack of childcare. However, parental involvement in children's education from an early 
age has a significant effect on educational achievement, and continues to do so into adolescence and adulthood (Sylva \& Melhulsh, 2004).

The school your child goes to is as much a status symbol as the car you drive or the estate you live in (Kaigai, 2011). The author further states that the parent and the child must submit some elaborate results which are used to determine the performance of the parent. Esther Njeri, a nominated counsellor reported to the Truth, Justice and Reconciliation Commission that many children are not accessing even the basic education although it is free because they are either forced by their parents to work on the farms to supplement the family income or they voluntarily choose to work to gain self .The quality of parental input in the first twenty five years of children's lives contributes greatly to what happens for the next forty five years or more (Daily Nation,2011). Quality parenting must therefore be addressed and enforced in any well-established society, for children to achieve their potential. However, parents also need to be supported in this role. Over the years, a considerable number of children on being sent home for school fees balances or indiscipline spend the better part of the term at home.This leads to dropping out of school while others just go back to sit for the final examinations (DEO, 2011).The DEO further reported that, when parents are invited for academic clinics, a good number prefer sending their own children who may be at home to represent them while others do not attend at all. Parents state that their wish is that their children just get the Kenya Certificate of Secondary Education certificate at the end of the four years course.Most pupils miss classes and accompany their parents to go and work on people's farms to earn extra cash or be paid with food such as potatoes or maize (Hussein, 2010). Due to lack of proper followup, Kieni-West District is faced with a high percentage of children not attaining quality grades. A considerable number of parents do not involve themselves in the academic work of their children which may contribute to low academic achievement (Daily Nation, 2011).

\subsection{Research Design}

\section{Methodology}

The research design adopted in this study was descriptive survey design. Both qualitative and quantitative techniques were used. By qualitative techniques, the researchers included open ended items where the respondents were given an opportunity to express their views. Quantitative techniques meant measuring numerical values. Quantitative techniques meant measuring numerical values. Measures of central tendency such as mode, mean, median, frequency and standard deviation were used. Data was categorized, themes established and coded. By use of this design the researcher intended to report the status of parental involvement in their children's education as it were in the schools studied.

\subsection{Sample Size and Sampling Procedure}

Stratified random sampling technique was used in this study where there were three groups namely the parents, teachers and form three students from the four educational zones in Kieni-West District. Form three students were purposively selected because they had been in school for a longer period and were settled while form one and two were excluded because they were still settling while form four being an examination class, were busy. Simple random sampling technique was used for parents and forms three students. They were thoroughly mixed and then $10 \%$ drawn for the sample one after the other without replacement. Sampled parents comprised of a combination of parents of form three students who had been sampled and others who had not.

\subsection{Research Instruments}

The research study used triangulation method in data collection. Questionnaires, interview schedules, document analysis and researchers' own observation were used. One questionnaire was administered to form three subject teachers and the other one to form three students'. A structured interview schedule for sampled parents focused on their involvement in the academic activities of their children.

\section{Results and Discussion}

Parents were asked to show their age (Fig. 1). 


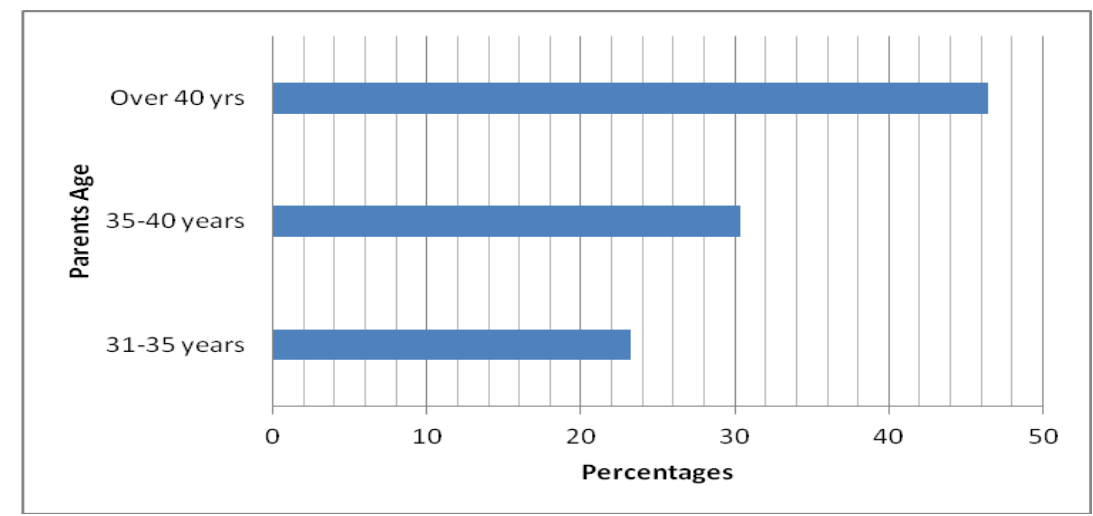

Figure 1: Parents' age

The results indicated that $46.4 \%$ of the parents were over 40 years followed by $30.4 \%$ in the age bracket of 35 40 years. In establishing the level of education (Fig. 2), 36.9\% of the parents interviewed had gone up to secondary school level which was $36.9 \%$, followed by primary school level at $27.8 \%$.

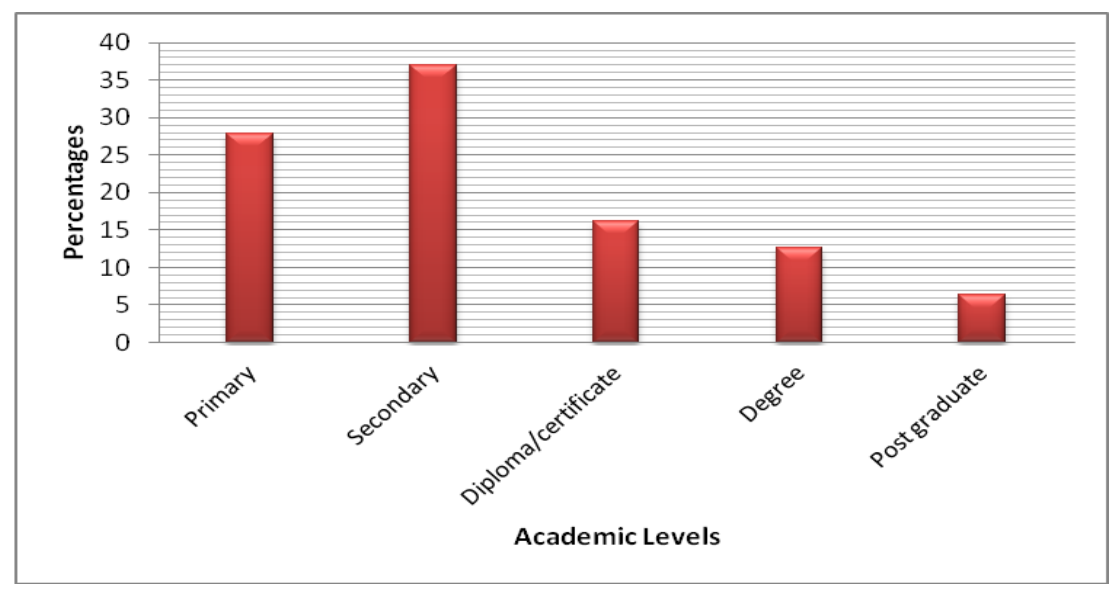

Figure 2: Parents' academic level

The researchers had asked the parents to indicate their income levels and the responses were as indicated in Fig. 3. The findings of the study indicated that parents who earned a monthly income level of Ksh. less than 5000 were $35.4 \%$, those who earned between 5001- 10000 recorded 31.9\%, and those with more than 15000 were $18.6 \%$. The findings indicate that most of the students came from low income earning households and this may lead to poor fees payment or delays resulting to the student being absent.

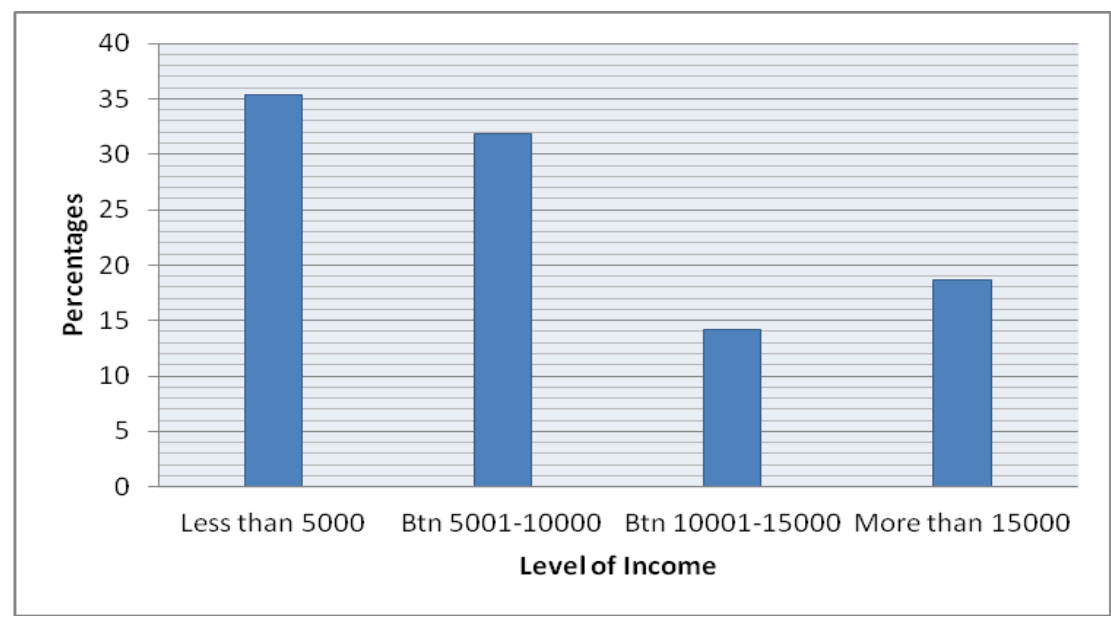

Figure 3: Parents' income level 
The researchers established that $84.7 \%$ of the parents participated in school events and activities while $15.3 \%$ did not (Fig. 4). This suggests a strong commitment by parents in school events and activities. This finding is different from a similar study carried out by Kirschenbaum (2000), who found that the most universal problem is poor attendance at school events that deal with educational topics, convey important information or require work to be done. The researchers found that the parents were committed and were part of the school's plan. This trend was important in understanding school performance and learning.

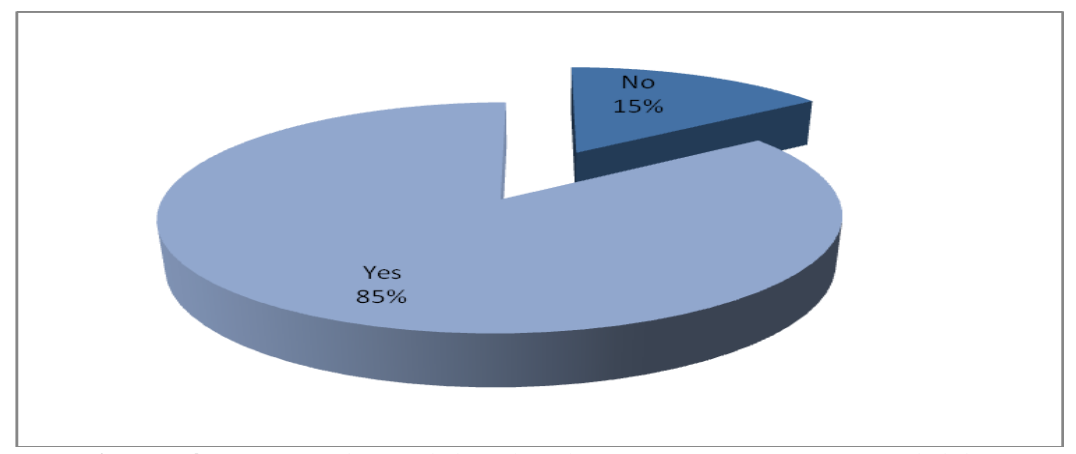

Figure 4 : Parents' participation in school events and activities

The study sought to further investigate why some parents were not able to attend and participate in school events and activities. The outcome was that a considerable percentage of $45 \%$ had no time to attend. Parents who worked away from home constituted $24 \%$ while those who were casual labourers and lacked permission from work place was $31 \%$ (Fig. 5). The findings are similar to studies carried out by Dwyer and Hecht (2001), who reported that parents feel they did not have enough time, given that they were busy with their leisure and activities.

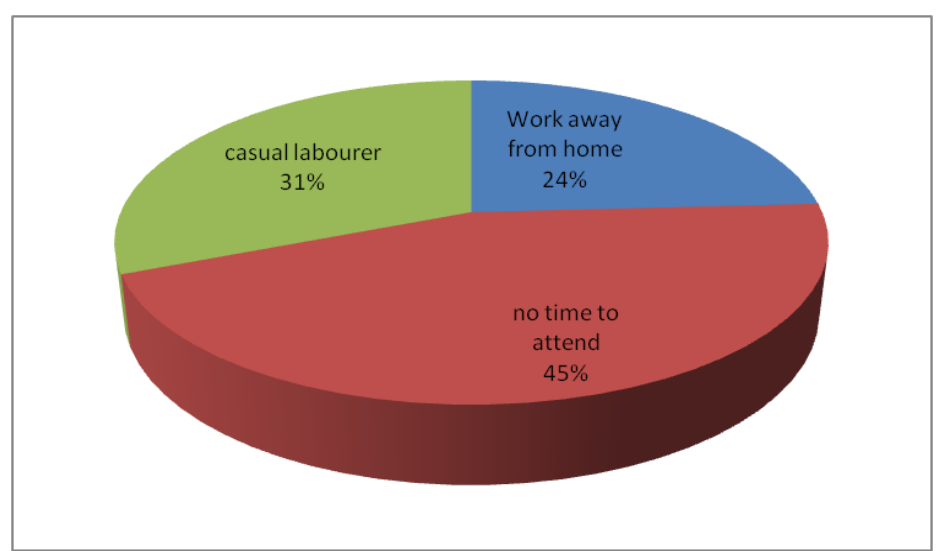

Figure 5:Reasons for parents not attending to school events

The researchers found out that parents engaged their children in holiday tuition (Fig. 6) was $72 \%$ while those who did not were $28 \%$. This situation suggests that parents support holiday tuition and are aware of its benefits to their children.

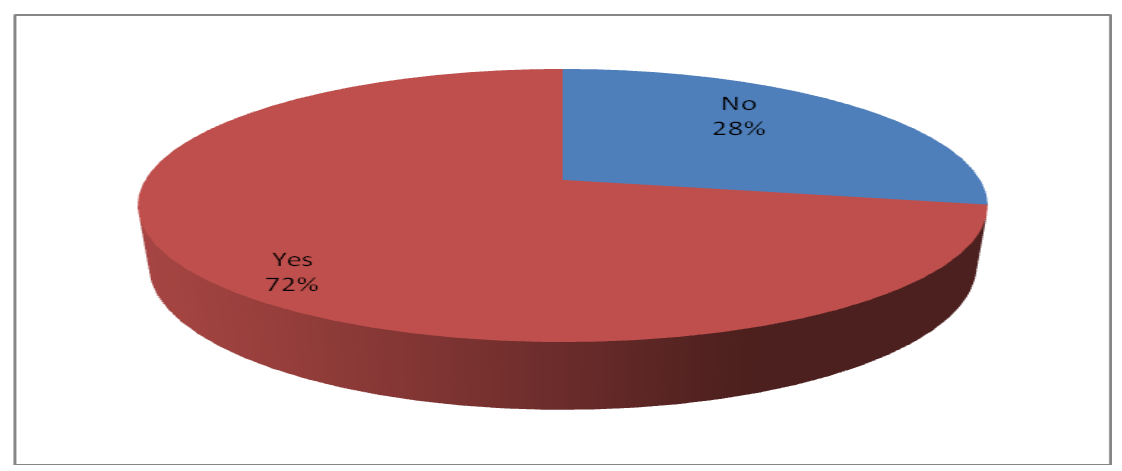

Figure 6: Parents responses regarding holiday tuition 
On the other hand, parents were asked to explain why they did not engage their children for holiday tuition (TABLE 1). Parents who did not engage their children for tuition had various reasons which included lack of money with the highest percentage of $73 \%$.

Table1 :Reasons for not engaging children in holiday tuition

\begin{tabular}{|l|l|}
\hline Response & Percentage \\
\hline Child to relax & 11 \\
\hline Poor performance & 16 \\
\hline No money & 73 \\
\hline Total & 100 \\
\hline
\end{tabular}

The study sought to investigate suggestions which the teachers would offer regarding curbing the experiences they face with parents in involvement in education achievement for their children (TABLE 2).

Table 2: Teachers' views regarding parents' needs in their children's academics

\begin{tabular}{llc}
\hline Response & Frequency & Percentage \\
\hline Seminar, workshop awareness campaign & 49 & 46 \\
Parents collaborations with teachers & 29 & 27 \\
More voluntary visits to schools by parents encouraged & 23 & 21 \\
Parents to be a source of motivation and role model & 6 & 6 \\
Total & 107 & 100 \\
\hline
\end{tabular}

The findings indicated that 49 teachers were for seminars and workshops that empower parents on their roles, 29 teachers said that parents collaborate with teachers and 23 teachers felt that parents should be encouraged to voluntarily visit schools for academic updates. As regards difficulties or painful experiences during the parents' school time, the study revealed that $80 \%$ experienced difficulties as compared to $20 \%$ who did not (Fig. 7).

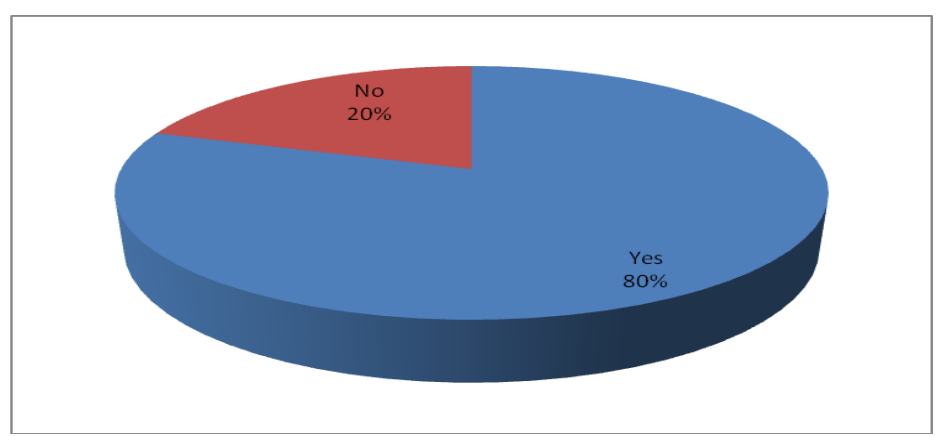

Figure 7: Difficulties and painful experiences

The study showed that up to $30 \%$ of the parents lacked school fees and $24 \%$ had parents with poor education background and did not know the importance of education. The findings indicated that parents experienced lack of school fees and their parents had a wanting education background. Their children were still experiencing the same which the researchers argue that there is a chain of low social economic status which needs to change for a better performance. This is likely to affect the achievement of the child as well. The study further sought to find out if parents were aware of whether parental involvement programmes (Fig. 8). The findings indicated that up to $68.8 \%$ of the parents interviewed were aware of the programmes while $31.2 \%$ were not.

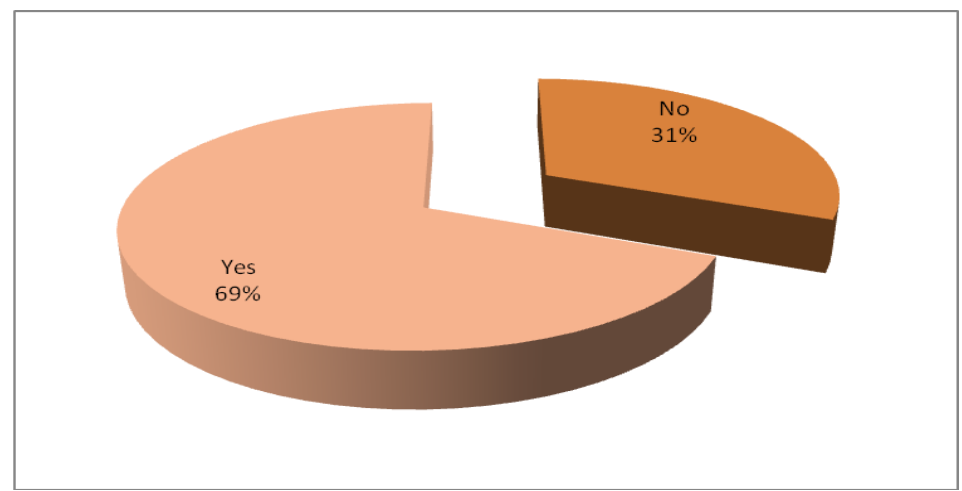

Figure 8: Parents'parental involvement programmes awareness 
The study further sought to investigate parents' sources of income (Fig. 9).

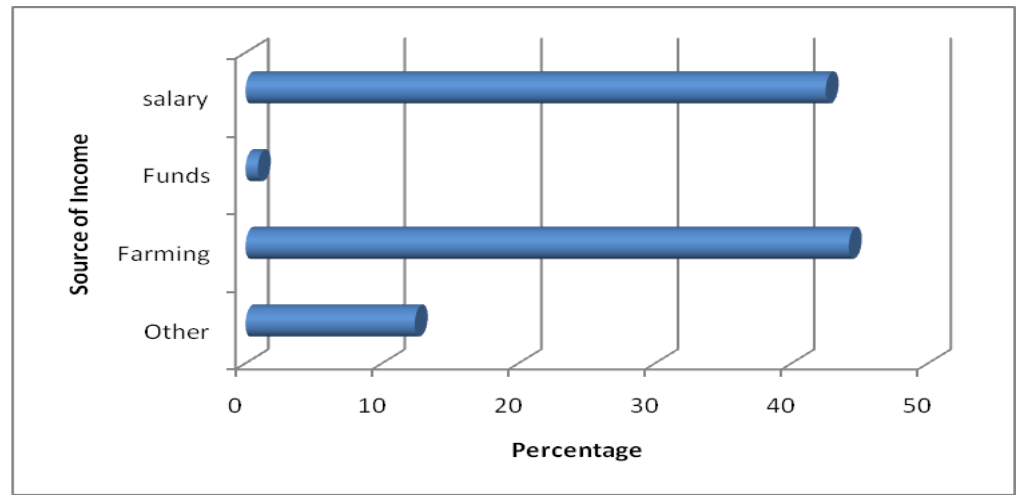

Figure 9: Parents' sources of income

The findings indicated that $44.2 \%$ of the parents were farmers while $42.5 \%$ depended on salaries, those who were funded were $0.9 \%$ while those with other sources were over $10 \%$. This finding suggests that when there is drought the parents would have fees payment problems and their children would be away from school due to fees balances or delays. The students would in the long run lose touch with some of the subject content covered in his or her absence which would impact negatively on results. The researchers asked the parents to state other sources of income other than salary, funds and farming. The responses were as follows (Fig. 10). This group comprised of 14 parents out of whom $57 \%$ were casuals while $22 \%$ relied on business. Most parents are casuals and their ability to secure and pay loans is limited so at the end of the day the probability of their children remaining at home for long due to fees balance increases. According to the researchers the fact that some parents were casuals and others were in business, means that there was a tendency of working more hours. When parents spend more time in work places, it means that they would not be in a position to offer quality time for their children. In return lack of time for the children's academic success would impact negatively on the performance of their children.

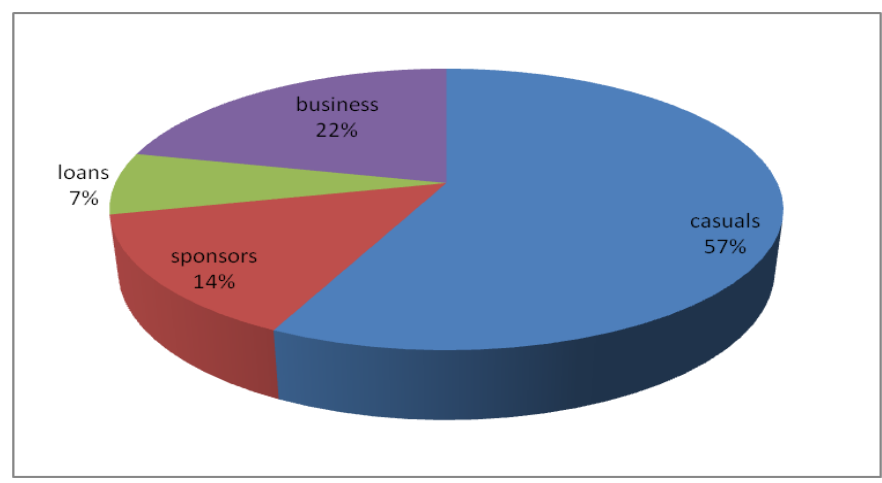

Figure 10: Other sources of income

The researchers wanted to know whether the parents were in a position to have their children remain in school throughout the term (Fig. 11).

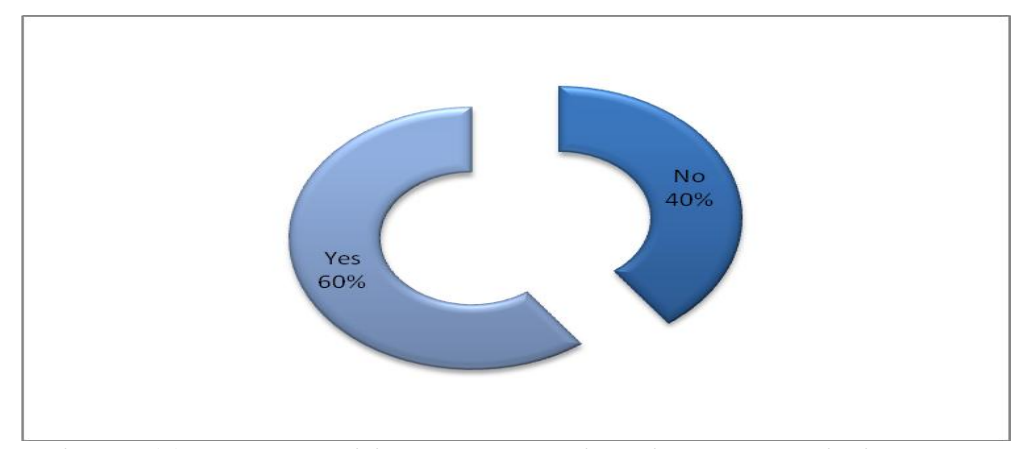

Figure 11:Parents ability to have their children remain in school 
The study indicated that $60.2 \%$ of the parents showed that their children remained in school throughout the term while $39.8 \%$ did not The researchers wanted to establish whether parents supported the teacher in English language the students were meant to speak while in school (Fig. 12).

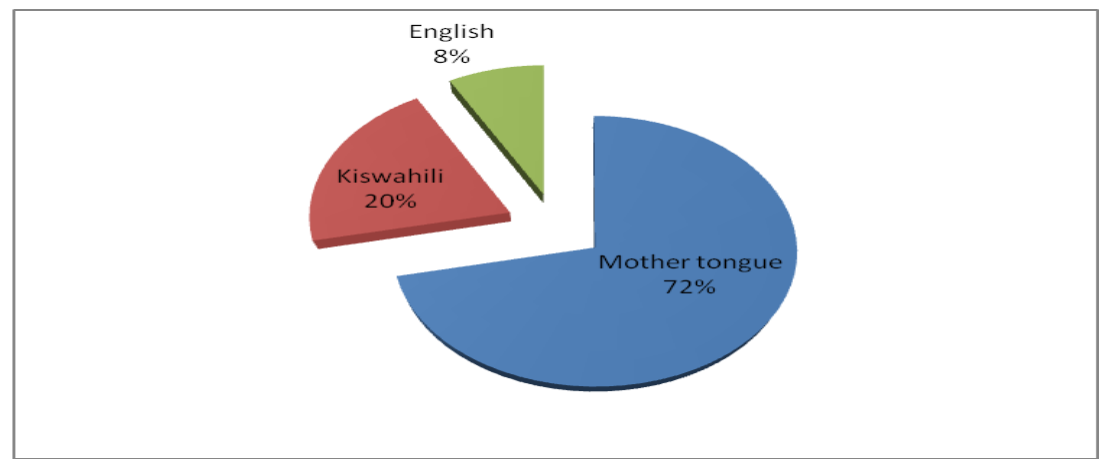

Figure 12: Languages parents speak to their children

The researchers asked the parents the languages they spoke to their children. The study showed that $71.7 \%$ of the parents spoke mother tongue to their children at home. The researchers felt that this affected the level of understanding in class and during the examination, whereby a student took more time to understand and answer the questions. At the end of the day a student who was exposed to English and Kiswahili was likely to do better than one who was used to mother tongue. When teachers were further probed on how experiences experienced by parents could be addressed, the outcomes were as shown in TABLE 3 that follows.

Table 3: Teachers' suggestions on overcoming challeges experienced by parents

\begin{tabular}{|l|l|}
\hline Response & Percentage \\
\hline Regular Academic Clinics & 19 \\
\hline Commitment & 22 \\
\hline Parental Programmes & 32 \\
\hline Instilling Discipline & 8 \\
\hline Sourcing Funds & 19 \\
\hline
\end{tabular}

The study showed that the teachers said that parental programmes should be prioritized in schools. The researchers found that organised parental programmes should take the centre stage to make parents aware of their roles in being actively involved in ensuring that their children perform well in the examinations. As noted earlier, the fact that parents had poor education background could have to some extent contributed to parents' lacking experience on how they should be involved in the academic achievement of their children. The study found difficulties parents faced while in school which included inability to pay school fees in full and in time ,some of their parents were not capable of providing personal effects at the appropriate time, calculators, mathematical sets and literature set books among others(Fig. 13).

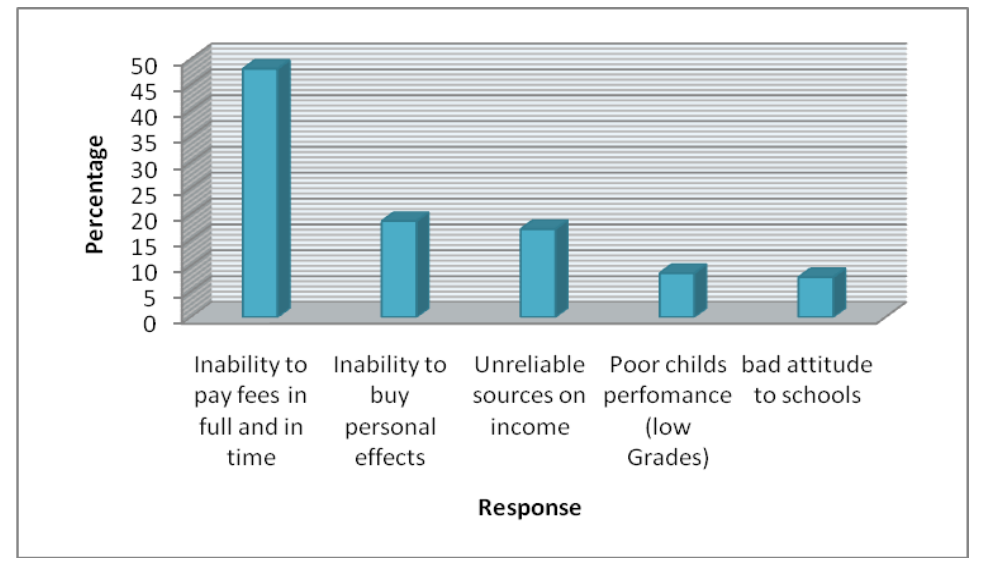

Figure 13: Experiences parents faced by parents as cited by students

The study further indicated that up to $33 \%$ of the students felt there was need to source for financial aids, $23 \%$ were for improved financial management of their parents. From the findings the researchers concludes that activities geared towards financing the parents so that they can pay school fees, buy 
supplementary books, pay library fee as well buy computers for education purposes would really improve the performance of the students. When the performance is improved the students compete favourably for marketable courses. The researchers further enquired on the Kenya Certificate of Secondary Education analysis for 2013 in the sampled schools. The researchers noted that parents were involved in the academic achievement but the performance in the national exam was wanting. The results showed that the scores were low compared to the input of the parents in their children's education in Kieni-West District (Fig.14).

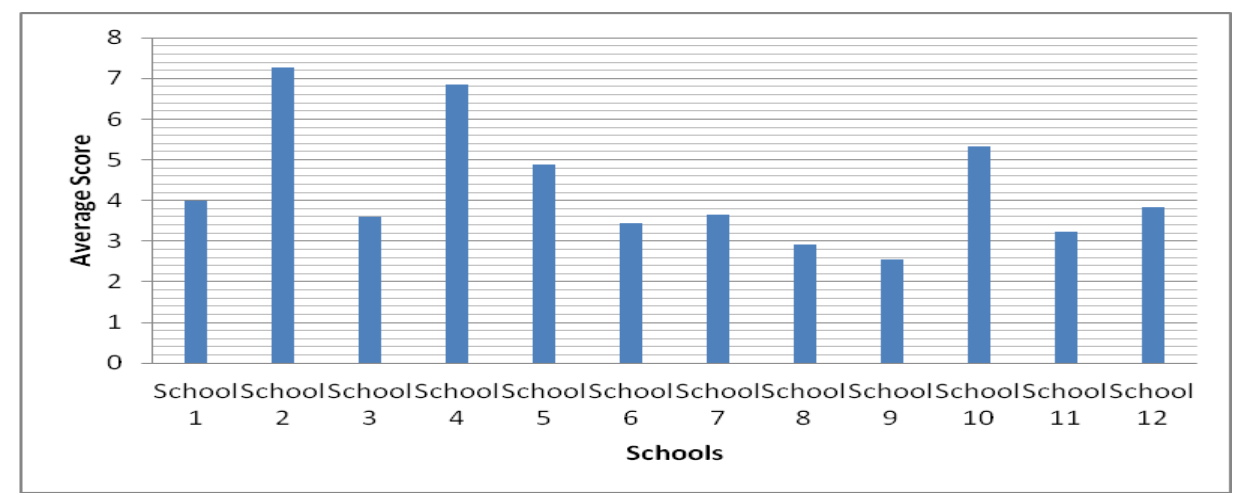

Figure14: KCSE average scores for the sampled school year 2013Conclusion

\section{Conclusions}

The study realized that even though parents were involved, the average performance was wanting which meant parents continued being involved but there was no value addition. The study realized that inability to pay school fees in time could have contributed to reduced teacher student contact hours which affect performance of the children preventing achievement of quality grades. Mother tongue was popular in that majority of the parents communicated to their children in it. The researchers argue that prior proper planning of the parents in their children's education prevents poor performance. There is need for parental awareness programmes aided by the government in public secondary schools in Kieni West, Nyeri County. It is paramount to mention that teachers also need to be very close to parents and clearly define their roles as early as their children join school. When parents are involved, children achieve more and everyone benefits in the sense that the school is recognized, parents have faith in the teachers and students are willing to stay.

\section{Acknowledgements}

In the course of writing this paper, we have received assistance from several people. We would like to appreciate the untiring contributions of certain persons for their support; encouragement and motivation which helped me bring this paper into a reality. This paper would not be complete without the help and invaluable support of the Almighty God for giving good health.Sincere thanks goes to the principals, teachers, students and parents of Kieni-West District public secondary schools for their participation in this study.

\section{Reference}

[1]. Bradley, R.H., \& Corwyn, R.F. (2002). 'Socioeconomic status and child development'. Annual Review of psychology.

[2]. D.E.O, Kieni West District Education Office (2011). Students performance in Kieni West District.

[3]. Dwyer, D.J, \& Hecht, J.B. (2001). Minimal parental involvement. Lincoln, IL: Academic Development Institute.

[4]. Eliason, C. \& Jenkins, L. (2003). A practical guide to early childhood curriculum ( $7^{\text {th }}$ Edition). New Jersey: Prentice Hall.

[5]. Hussein, O. (2010). Programme to empower disabled persons, Reject issue 009, January 1-15-2010.

[6]. Green Leaf,R.K.(2000, January).Homework for families. High school magazine.

[7]. Grusec, J.E., Goodnow.J.J., \& Kuezynski, L., (2000). New directions to children's acquisition of values. Child Development.

[8]. Kirschenbaum, H. (2000, January). The principal's view. The High school Magazine.

[9]. Mugenda, O.M \& Mugenda, A.G. (2003): Research Methods:Quantitative and Qualitative Approaches.Nairobi:Acts press.

[10]. Njoki K., (2011). Education for modern day parents, Daily Nation, $10^{\text {th }}$ September, Column Two.

[11]. Ryan, T. (2005). Using information in Education. Available at http://www.parental.//involvement/htm. Accessed 20/03/2003.

[12]. Simon, B.S. (2000). Predictors of high school and family partnerships and the influence

[13]. of partnerships on student success. Doctoral dissertion, John Hopkins. University, 2000. Available at:National Network of Partnership Schools Web site:http://www.csos.jhu.edu/p2000/type2/issue10/tttype2j4.htm12 Accessed on 13/09/2006.

[14]. Sylva, K. \& Melhulsh, B. (2004) .Effective Pre-school Education. Final Report. DFES. London: institute of Education.

[15]. Tella, A. \& Tella, A. (2003). Parental involvement, home background, and school environment as determinant of academic achievement of secondary school students in Osun state, Nigeria. African Journal of cross-cultural psychology and sport facilitation. 